\title{
Alterations in Intrinsic Membrane Properties and the Axon Initial Segment in a Mouse Model of Angelman Syndrome
}

\author{
Hanoch Kaphzan, ${ }^{1}$ Shelly A. Buffington, ${ }^{2}$ Joo In Jung, ${ }^{1}$ Matthew N. Rasband, ${ }^{2}$ and Eric Klann ${ }^{1}$ \\ ${ }^{1}$ Center for Neural Science, New York University, New York, New York 10003, and ${ }^{2}$ Department of Neuroscience, Baylor College of Medicine, Houston, \\ Texas 77030
}

The axon initial segment (AIS) is the site of action potential initiation in neurons. Recent studies have demonstrated activity-dependent regulation of the AIS, including homeostatic changes in AIS length, membrane excitability, and the localization of voltage-gated Na ${ }^{+}$ channels. The neurodevelopmental disorder Angelman syndrome (AS) is usually caused by the deletion of small portions of the maternal copy of chromosome 15, which includes the UBE3A gene. A mouse model of AS has been generated and these mice exhibit multiple neurological abnormalities similar to those observed in humans. We examined intrinsic properties of pyramidal neurons in hippocampal area CA1 from AS model mice and observed alterations in resting membrane potential, threshold potential, and action potential amplitude. The altered intrinsic properties in the AS mice were correlated with significant increases in the expression of the $\alpha 1$ subunit of $\mathrm{Na} / \mathrm{K}-\mathrm{ATPase}(\alpha 1-\mathrm{NaKA})$, the $\mathrm{Na}^{+}$channel NaV1.6, and the AIS anchoring protein ankyrin-G, as well as an increase in length of the AIS. These findings are the first evidence for pathology of intrinsic membrane properties and AIS-specific changes in AS, a neurodevelopmental disorder associated with autism.

\section{Introduction}

Angelman syndrome (AS) is a neurodevelopmental disorder that is associated with symptoms that include autism, mental impairment, motor abnormalities, and epilepsy (Lossie et al., 2001; Williams et al., 2006). In most cases, AS is caused by the deletion of small portions of the maternal copy of chromosome 15, which includes the UBE3A gene (Knoll et al., 1989; Kishino et al., 1997; Matsuura et al., 1997; Sutcliffe et al., 1997), via a phenomenon known as "imprinting," and is observed in specific brain areas (Albrecht et al., 1997; Jiang et al., 1998a). The UBE3A gene encodes an enzyme termed ubiquitin ligase E3A (also termed E6AP), which is one of a family of enzymes that covalently attaches polyubiquitin chains to proteins to signal for their recognition and degradation by the $26 \mathrm{~S}$ proteasome. A mouse model of AS has been generated that exhibits seizures and impaired motor function, as well as abnormalities in neuronal morphology, synaptic function, and cognition that correlate with neurological alterations observed in humans with AS (Jiang et al., 1998b).

One of the main loci in the brain that has been shown to be impaired in AS model mice is the hippocampus. Hippocampusdependent learning and memory as well as long-term potentiation, a cellular model for learning and memory, are both impaired in AS model mice (Jiang et al., 1998b; van Woerden et

\footnotetext{
Received Aug. 12, 2011; revised 0ct. 13, 2011; accepted 0ct. 19, 2011.

Author contributions: H.K., S.A.B., M.N.R., and E.K. designed research; H.K., S.A.B., and J.I.J. performed research; H.K., S.A.B., M.N.R., and E.K. analyzed data; H.K., S.A.B., M.N.R., and E.K. wrote the paper.

This work was supported by National Institutes of Health Grants NS034007 and NS047384 (E.K.), NS044916 (M.N.R.), and NS073295 (S.A.B.) and the Angelman Syndrome Foundation (E.K).

The authors declare no competing financial interests.

Correspondence should be addressed to Dr. Eric Klann, Center for Neural Science, New York University, New York, NY 10003. E-mail: eklann@cns.nyu.edu.

DOI:10.1523/JNEUROSCI.4162-11.2011

Copyright $\odot 2011$ the authors $\quad 0270-6474 / 11 / 3117637-12 \$ 15.00 / 0$
}

al., 2007). Neurons are divided into two major compartments, the somatodendritic compartment and the axonal compartment, each with its own unique structure and protein composition. Previous studies of AS model mice have focused exclusively on abnormalities in synaptic structure and function, with no studies examining the axonal compartment or intrinsic membrane properties. Changes in axonal excitability affect action potential firing probability and could contribute to AS pathology.

Action potentials are initiated at the axon initial segment (AIS), a specialized membrane domain characterized by highdensity clusters of voltage-gated $\mathrm{Na}^{+}$and $\mathrm{K}^{+}$channels that regulate neuronal output (Kole et al., 2008). Voltage-gated $\mathrm{Na}^{+}$ channels are recruited to the AIS and stabilized at the membrane through interactions with ankyrin-G (Zhou et al., 1998; Garrido et al., 2003; Lemaillet et al., 2003). Thus, action potential initiation threshold is lowest at the AIS (Kole and Stuart, 2008). Recent evidence shows that neuronal activity can alter AIS structure, leading to changes in neuronal excitability (Grubb and Burrone, 2010; Kuba et al., 2010); therefore, plastic changes at the AIS may contribute to homeostatic regulation of membrane excitability.

Here, we examined the intrinsic properties of pyramidal neurons in hippocampal area CA1 from AS model mice and observed altered intrinsic membrane properties that were correlated with significant increases in the expression of $\alpha 1$-NaKA and specific AIS proteins, as well as an increase in length of the AIS. These findings are intriguing given recent studies that indicate that the AIS can be modified in response to altered neuronal excitability (Grubb and Burrone, 2010; Kuba et al., 2010). Thus, our results suggest that altered intrinsic membrane properties and structural changes at the AIS contribute to pathophysiology in AS model mice. 


\section{Materials and Methods}

Mice. AS model mice on a C57BL/6 background, ages 8-12 weeks (unless otherwise specified), were generated and genotyped using specific primers as described previously (Jiang et al., 1998b). Mice for experiments were bred from a female that was a heterozygous for the deletion of $U b e 3 a$ from a paternal origin $\left(U b e 3 a^{p-/ m+}\right)$ and a wild-type male. For all experiments using AS model mice, wild-type littermates were used as controls. All mice were housed in the Transgenic Mouse Facility of New York University, compliant with the NIH Guide for Care and Use of Laboratory Animals. Mice were kept on a $12 \mathrm{~h}$ light/dark cycle, with food pellets and water ad libitum.

Tissue preparation for Western blots. AS mice and wild-type littermates mice were decapitated, the brain was quickly extracted, and hippocampi from both hemispheres were removed in an ice-cold cutting solution (CS) containing the following (in $\mathrm{mm}$ ): 110 sucrose, $60 \mathrm{NaCl}, 3 \mathrm{KCl}, 1.25 \mathrm{NaH}_{2} \mathrm{PO}_{4}, 28 \mathrm{NaHCO}_{3}$, $0.5 \mathrm{CaCl}_{2}, 7 \mathrm{MgCl}_{2}, 5$ glucose, and 0.6 ascorbate, and immediately snap-frozen on dry ice. Frozen hippocampi were placed in ice-cold lysis buffer containing the following (in $\mathrm{mm}$ ): 40 HEPES, pH 7.5, $150 \mathrm{NaCl}, 10$ pyrophosphate, 10 glycerophosphate, 1 EDTA and $0.3 \%$ CHAPS, Protease Inhibitor II, Phosphatase Inhibitor Cocktail I, II (Sigma), and homogenized by sonication. Protein quantification was performed with BCA (bicinchoninic acid) protein assay reagent (Thermo Scientific).

Western blots. After homogenization and protein quantification, protein samples were added to $\beta$-mercaptoethanol-containing SDS sample buffer and heated for $2 \mathrm{~min}$ in $60^{\circ} \mathrm{C}$ before loading on SDS-polyacrylamide gels. After heating the samples, $4-20 \mu \mathrm{g}$ of protein (depending on the specific protein and the linear range of detection) were loaded on $4-12 \%$ gradient SDS-PAGE gels, resolved, transferred to PVDF membranes, and probed with primary antibodies using standard techniques. The primary antibodies and the dilutions for the Western blots used in these studies are as follows: ankyrin-B 1:1000 (Invitrogen); NaV1.6 1:500 (Sigma-Aldrich); ERK 1:1000 (Cell Signaling Technology); NF-186, PP2A 1:1000 (Millipore); Kv1.1, Kv1.2, and KCNQ2 1:500, NaV1.1 and NaV1.2 1:1000 (Neuromab); $\alpha 1$-NaKA, NrCAM, HCN2/4 1:1000 (Abcam); FGF14 1:200, cofilin, KCNQ3, and HCN1 1:500, ankyrin-G, IP3R, and $\beta I V-$ spectrin 1:1000, $\beta$-actin and GAPDH 1:5000 (Santa Cruz Biotechnology); $\alpha 3$-NaKA 1:1000 (Thermo Scientific). Secondary antibodies were HRP conjugated. All blots were developed using enhanced chemiluminescence detection (GE Healthcare). The bands of each Western blot were imaged and quantified using the KODAK 4000MM imaging system. All signals were obtained in the linear range for each antibody, normalized by total protein, and quantified via densitometry. Data represent mean \pm SEM. A Student's $t$ test was used for Western blot analysis with $p<0.05$ as significance criteria.

Intracellular electrophysiology. Brains from AS model mice and their wild-type littermates were quickly removed and transverse hippocampal slices $(300 \mu \mathrm{m})$ were isolated with a Leica VT1200 Vibratome. This part of the slicing was done in ice-cold cutting solution (in mM): 110 sucrose,
Table 1. Passive intrinsic properties of CA1 pyramidal cells

\begin{tabular}{llll}
\hline Parameter & WT & AS & $p$ value \\
\hline Resting potential $(\mathrm{mV})$ & $-61.7( \pm 1.5)$ & $-66.4( \pm 1.5)$ & $<0.05$ \\
Time constant & $29.2(1.9)$ & $29.0(2.0)$ & ns \\
Input resistance $(\mathrm{M} \Omega)$ & $237.8(13.2)$ & $239.8(13.1)$ & ns \\
\hline
\end{tabular}

Altered passive intrinsic properties in hippocampal CA1 pyramidal neurons from AS model mice and their wild-type littermates. Resting potential is significantly more hyperpolarized in AS mice (WT: $n=15$ cells, 5 mice; AS: $n=15$ cells, 5 mice).
A
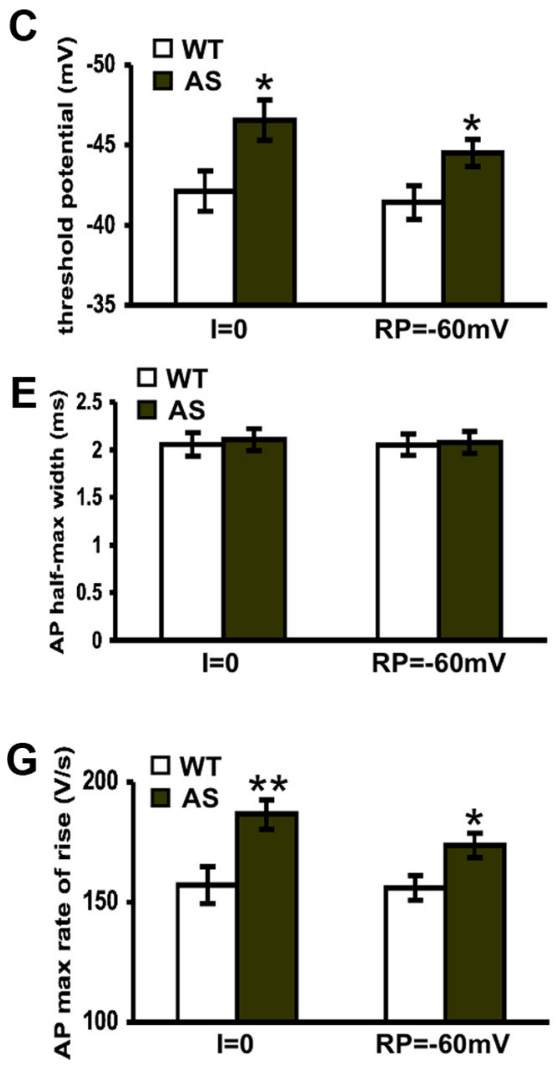

B

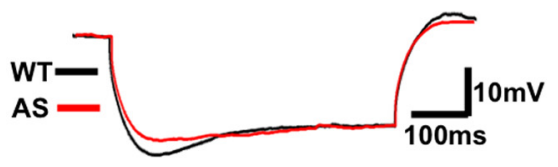

Figure 1. Altered intrinsic properties in hippocampalCA1 pyramidal neurons from AS model mice and their wild-type littermates with eitherno current injection $(I=0)$ or constant current injection to bring the resting potential to $-60 \mathrm{mV}$. $A$, Sag potential. $B$, Representative superimposed traces of sag potentials from wild-type (WT) and AS mice. C, Threshold potential. $\boldsymbol{D}$, Action potential amplitude. $\boldsymbol{E}$, Action potential full-width at half-maximum. $\boldsymbol{F}$, Representative superimposed traces of action potentials from WT and AS mice. $\mathbf{G}$, Maximal rate of rise (dV/dt) of the action potential. $\boldsymbol{H}$,Sample of superimposed action potential trace from an AS mouse on its related dV/dt curve to illustrate the method for determining the threshold. Blue point is the projection of $30 \mathrm{~V} / \mathrm{s}$ from the $\mathrm{dV} / \mathrm{d} t$ curve on the action potential trace, which shows the deflection point of the threshold. (Forall $/=0$ experiments, WT: $n=15$ cells, 5 mice; AS: $n=15$ cells, 5 mice; for all current injection to the resting potential of $-60 \mathrm{mV}$, WT: $n=18$ cells, 5 mice; AS: $n=18$ cells, 5 mice). Asterisks denote statistical significance $\left({ }^{*} p<0.05 ;{ }^{* *} p<0.01\right)$ with a Student's ttest.

$60 \mathrm{NaCl}, 3 \mathrm{KCl}, 1.25 \mathrm{NaH}_{2} \mathrm{PO}_{4}, 28 \mathrm{NaHCO}_{3}, 0.5 \mathrm{CaCl}_{2}, 7 \mathrm{MgCl}_{2}, 5$ glucose, 0.6 ascorbate. Slices recovered for $45 \mathrm{~min}$ at $35^{\circ} \mathrm{C}$ in artificial CSF (ACSF) containing the following (in $\mathrm{mM}$ ): $125 \mathrm{NaCl}, 2.5 \mathrm{KCl}, 1.25$ $\mathrm{NaH}_{2} \mathrm{PO}_{4}, 25 \mathrm{NaHCO}_{3}, 25$ D-glucose, $2 \mathrm{CaCl}_{2}$, and $1 \mathrm{MgCl}_{2} \mathrm{ACSF}$, followed by additional recovery for $30 \mathrm{~min}$ in room-temperature ACSF. After initial recovery, slices were placed in a submerged chamber and maintained at $22^{\circ} \mathrm{C}$ in ACSF $(2 \mathrm{ml} / \mathrm{min})$. Slices were allowed to recover for an additional $60 \mathrm{~min}$ on the electrophysiology rig before experimen- 
A
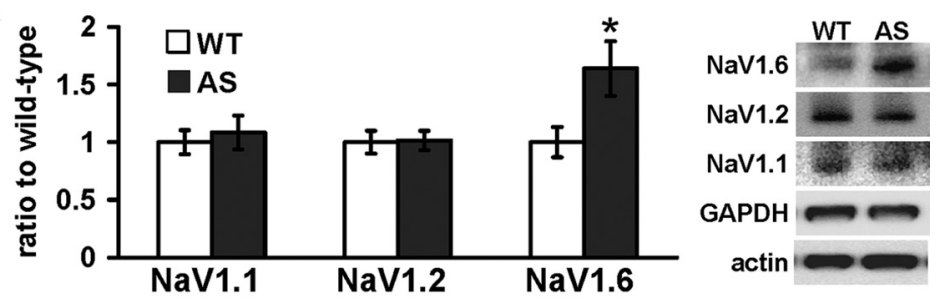

B

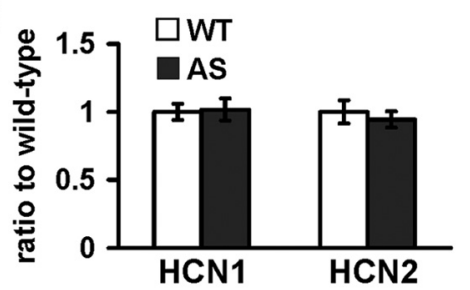

C

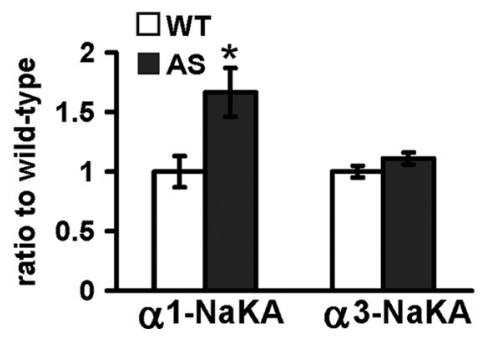

Figure 2. Increased expression of NaV1.6 and $\alpha 1$-NaKA in AS model mice. $\boldsymbol{A}-\boldsymbol{C}$, Western blots of hippocampal homogenates from AS mice and their WT littermates were probed with antibodies to proteins potentially related to the altered intrinsic properties in the AS mice. Actin and GAPDH were used as loading controls and were quantified as a reference in the same blot for each protein. (WT: $n=9$ mice; AS: $n=11$ mice). ${ }^{*}$ denotes statistical significance $(p<0.05)$ with a Student's $t$ test.

tation. All solutions were constantly carboxygenated with 95\% $\mathrm{O}_{2}+5 \%$ $\mathrm{CO}_{2}$. Hippocampal CA1 pyramidal cells were illuminated and visualized using a $\times 60$ water-immersion objective mounted on a fixed-stage microscope (BX51-WI, Olympus), and the image was displayed on a video monitor using a charge-coupled device camera (Hamamatsu). Recordings were amplified by multiclamp 700B and digitized by Digidata 1440 (Molecular Devices). The recording electrode was pulled from a borosilicate glass pipette (3-5 M $\Omega$ ) using an electrode puller (P-97; Sutter Instruments) and filled with a K-gluconate-based internal solution (in $\mathrm{mM}$ ): 120 K-gluconate, $20 \mathrm{KCl}, 10 \mathrm{HEPES}, 2 \mathrm{MgCl}_{2}, 4 \mathrm{Na}_{2} \mathrm{ATP}, 0.5$ TrisGTP, 14 phosphocreatine, osmolarity $290 \mathrm{mOsm}$ and $\mathrm{pH}$ 7.3. The recording glass pipettes were patched onto the CA1 pyramidal cells' soma region. Voltages for liquid junction potential $(+14 \mathrm{mV})$ were not corrected online. All current-clamp recordings were low-pass filtered at $10 \mathrm{kHz}$ and sampled at $50 \mathrm{kHz}$. Series resistance was compensated and only series resistance $<20 \mathrm{M} \Omega$ was included in dataset. Pipette capacitance was $\sim 99 \%$ compensated. The method for measuring active intrinsic properties was based on a modified version of Kole et al. (2008). After initial assessment of the current required to induce an action potential at $15 \mathrm{~ms}$ from the start of the current injection with large steps (50 pA), we injected a series of brief depolarizing currents for $30 \mathrm{~ms}$ in steps of $10 \mathrm{pA}$ increments. The first action potential that appeared on the $15 \mathrm{~ms}$ time point was analyzed. A curve of $\mathrm{d} V / \mathrm{d} t$ was created for that trace, and threshold was considered as the 30 $\mathrm{V} / \mathrm{s}$ point in the rising slope of the action potential. Series resistance, input resistance, and membrane capacitance were monitored during the entire experiment. Changes of these parameters, from beginning to end of experiment, larger than $10 \%$ were criteria for exclusion of data. Data analysis was done with Clampfit (Molecular Devices). Two-tailed Student's $t$ test was used for electrophysiological data analysis with $p<0.05$ as significance criterion.

Immunostaining. Mice were deeply anesthetized with isoflurane before transcardial perfusion with ice-cold $4 \%$ PFA in $0.1 \mathrm{M} \mathrm{Na}$-phosphate buffer (PB, pH 7.2). Brains were postfixed in 4\% PFA $0.1 \mathrm{~m} \mathrm{~PB}$ for $1 \mathrm{~h}$ and equilibrated in $20 \%$ sucrose $0.1 \mathrm{M} \mathrm{PB}$ over $48 \mathrm{~h}$. Afterward, $25 \mu \mathrm{m}$ coro- nal slices containing the hippocampal formation were cut on a microtome and washed in $0.1 \mathrm{M}$ PB. Slices were mounted on gelatincoated coverslips, then blocked in $10 \%$ normal goat serum 0.1 м PB containing $0.3 \%$ TX-100 (PBTgs). Tissue was incubated overnight at $4^{\circ} \mathrm{C}$ in primary antibodies diluted in PBTgs. Primary antibodies were removed by washing the tissue 3 times for 5 min with PBTgs. Alexa594-conjugated goat anti-mouse and Alexa488-conjugated goat anti-rabbit $(1: 1000)$ secondary antibodies diluted in PBTgs were applied for $1 \mathrm{~h}$ at RT and used to visualize primary antibodies. Fluorescent dye-conjugated secondary antibodies were purchased from Invitrogen. Excess secondary antibodies were removed by consecutive $5 \mathrm{~min}$ washes with PBTgs, $0.1 \mathrm{M} \mathrm{PB}$, and $0.05 \mathrm{M}$ PB. Fluorescence imaging was performed on an AxioImager Z1 microscope (Carl Zeiss MicroImaging) fitted with an AxioCam digital camera (Carl Zeiss MicroImaging). AxioVision acquisition software (Carl Zeiss MicroImaging) was used for collection of images. Comparison of WT and AS tissue was performed on slices prepared in parallel and images were acquired at identical exposure times. Experiments were performed at least in triplicate. Fluorescence intensity (F.I.) was measured using ImageJ (NIH). In some images, contrast and brightness were subsequently adjusted in a linear fashion using Photoshop (Adobe); any adjustments made to one image were applied to all images in the same dataset. No additional processing of images was performed.

Antibodies for immunostaining. The following primary antibodies were used: rabbit anti-Nav1.6 (Rasband et al., 2003), mouse anti- $\alpha 1-\mathrm{NaKA}$ (Millipore, clone C464.6), mouse anti- $\alpha 3$-NaKA (Thermo Scientific), rabbit anti- $\beta$ IV-spectrin (Yang et al., 2004), mouse anti-ankyrinB (NeuroMab, clone N105/17), mouse anti-ankyrinG (NeuroMab, clone N106/ 36), mouse anti-neurofascin186 (clone L11A/41.6) (Schafer et al., 2004), rabbit anti-NrCAM (Abcam, clone ab24344), mouse anti-Pan Nav (Sigma, clone K58/35), mouse anti-FGF14 (NeuroMab, clone N56/21), rabbit anti-Kv1.2 (Rhodes et al., 1995), and rabbit anti-calbindin (Sigma, C2724). Hoechst staining was used to identify cell bodies in a subset of tissue slices.

AIS length quantification. AIS length was determined by line-scan length quantification of ankyrin G immunosignal in Image (NIH). For quantification, we measured the length of AIS contained within either a single image plane or through three-dimensional space in consecutive $Z$-stack images. Anti-ankG immunosignal was uniformly distributed throughout the AIS, providing a stark contrast in fluorescence intensity values at the axon-hillock-to-AIS and AIS-to-distal-axon transitions. Thus, to determine AIS length, we generated fluorescence intensity plots of ankG immunoreactivity and calculated the first derivative of the resulting intensity curve. The start and endpoints of the AIS were defined as the maximum and minimum values, respectively, of the derivative curve.

Statistical analysis. Two-tailed Student's $t$ tests and ANOVA (two-way or repeated measures) were used where appropriate. Results are displayed as mean \pm SEM.

\section{Results}

CA1 pyramidal neurons exhibit altered intrinsic passive and active membrane properties

Because AS model mice exhibit aberrant hippocampal function, we examined the intrinsic properties of hippocampal CA1 pyra- 

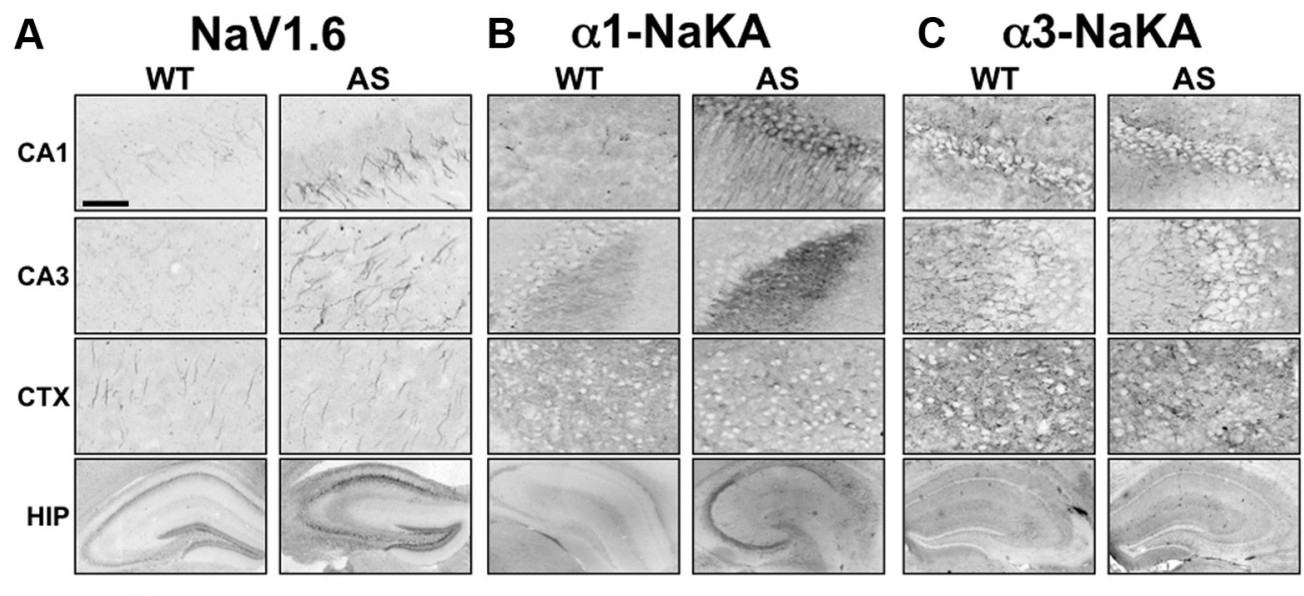

D

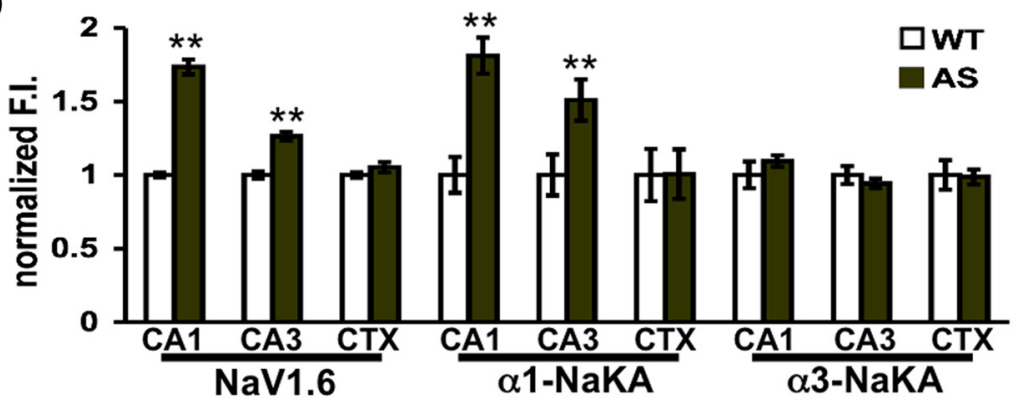

$\mathbf{E}$
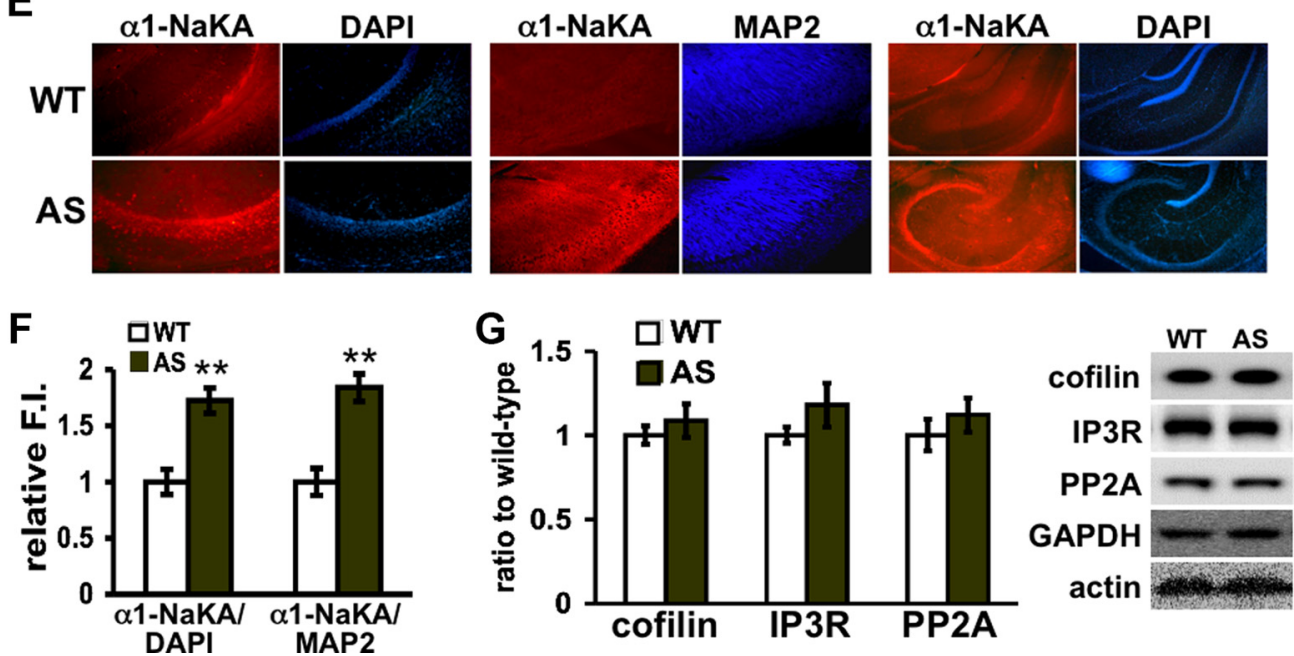

Figure 3. Localization of the increased levels of NaV1.6 and $\alpha 1$-NaKA in AS model mice. $\boldsymbol{A}-\mathbf{C}$, If scans of NaV1.6, $\alpha 1-N a K A$, and $\alpha 3$-NaKA respectively, in hippocampal areas CA1 and CA3, and the somatosensory cortex. The bottom frame in each column of all panels is an overview of the entire hippocampal region. Expression of NaV1.6( $(A)$ and $\alpha 1$-NaKA $(\boldsymbol{B})$ is increased in pyramidal neurons of hippocampal subregions $C A 1$ and $C A 3$, but not in the somatosensory cortex. $C$, $\alpha 3$-NaKA IF is similar between AS mice and WT littermates. Scale bar, $40 \mu \mathrm{m}$. D, Quantification of F.I. in the various subregions (WT and AS: $n=$ $30-40$ slices, 4 mice for NaV1.6; WT and AS: $n=7$ slices, 4 mice for $\alpha 1$-NaKA; WT and AS: $n=12,4$ mice for $\alpha 3$-NaKA). E, IF of $\alpha 1$-NaKA in hippocampal area CA1 shows increase in the soma area (taken as a ratio to DAPI) and in the dendritic area (taken as a ratio to MAP2). The last two scans on the right side of each row is an overview of the entire hippocampal region. $F$, Quantification of F.I. results of relative $\alpha 1$-NaKA in the CA1 intracellular subregions (soma and dendrites). G, Western blot analysis of proteins that interact with $\alpha 1$-NaKA (cofilin, IP3R, and PP2A) from hippocampal homogenates shows no alterations in their expression in AS mice (WT: $n=9$ mice; $A S: n=11$ mice). ${ }^{* *}$ denotes statistical significance $(p<0.01)$ with a Student's $t$ test.

midal neurons in AS model mice. The intrinsic properties were measured with whole-cell recordings in current-clamp mode. Examination of passive intrinsic properties revealed that the initial resting potential in the AS mice was more hyperpolarized when compared to wild-type littermates (Table 1). Time constants and input resistances of CA1 pyramidal neurons for both genotypes were similar (Table 1). The sag potential was significantly smaller (Fig. $1 A, B$ ) and the threshold potential was lower in AS mice, similar to the resting potential (Fig. 1C). We also found that the action potential amplitude and its maximal rate of rise $(\mathrm{d} V / \mathrm{d} t)$ were larger in AS mice than in wild-type mice, but the action potential full-width at half-maximum was similar (Fig. $1 D-G)$. To determine whether the aforementioned differences in intrinsic properties were a consequence of hyperpolarization of the resting potential, we examined these properties in current-clamp mode while holding the CA1 pyramidal neurons at a resting potential of $-60 \mathrm{mV}$ with current injection. Under these conditions, the sag potential in the AS mice was no longer different from wild-type mice (Fig. $1 A$ ), but all of the other parameters remained significantly different (Fig. $1 C-G$ ). These dissimilarities in the intrinsic properties 
A
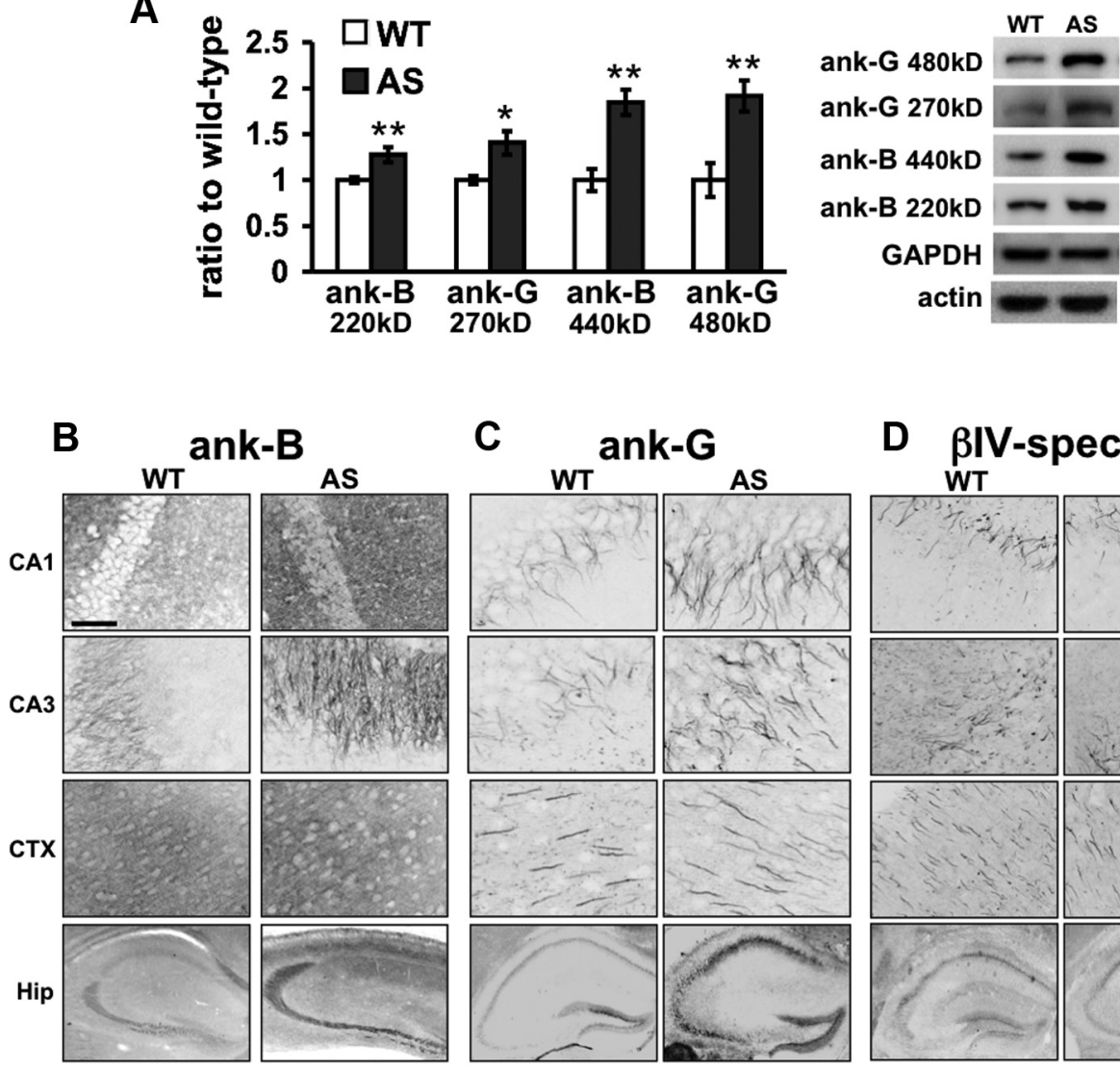

D $\quad$ IIV-spectrin

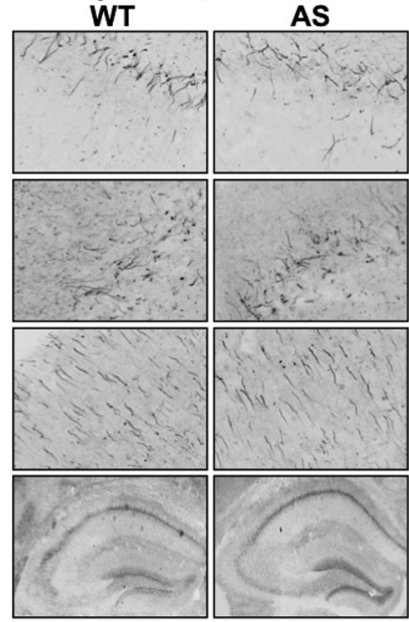

E

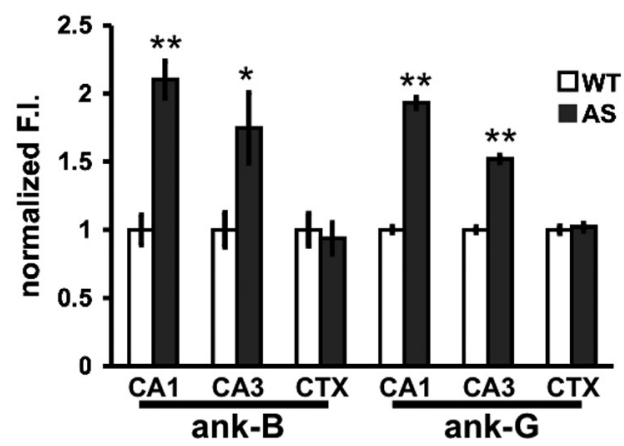

Figure 4. Increased expression of ankyrin-B and ankyrin-G in the hippocampus of AS model mice. $A$, Western blots of hippocampal homogenates from AS mice and their WT littermates were probed with antibodies to ankyrin-B and ankyrin- $G$ (WT: $n=9$ mice; $A S: n=11$ mice). $B, C$, IF of ankyrin- $B(B)$ and ankyrin- $G(C)$ confirms that increased expression is in hippocampal subregions CA1 and CA3, but not the somatosensory cortex. Scale bar, $40 \mu \mathrm{m}$. D, IF scans of $\beta \mathrm{IV}$-spectrin shows no alteration in the AIS of the hippocampus of AS mice. $\boldsymbol{E}$, Quantification of F.I. results for ankyrin-B and ankyrin-G in the various subregions. (WT and AS: $n=6$ slices, 4 mice). Asterisks denote statistical significance $\left({ }^{*} p<0.05 ;{ }^{* *} p<0.01\right.$ ) with a Student's $t$ test.

of CA1 pyramidal neurons in AS mice and their wild-type littermates suggest that there is a substantial difference in excitability, reflecting alterations in the ionic currents through the membrane during both the resting "passive" state and the firing "active" state of the neurons, and that they are not a mere reflection of the more hyperpolarized resting membrane potential. A sample trace of an action potential from an AS mouse is shown in Figure $1 H$, to illustrate the method for determining the threshold of an action potential and its maximal rate of rise.

The expression of NaV1.6 and $\alpha 1-\mathrm{NaKA}$ is increased in the AS hippocampus

We proceeded to determine the protein expression levels of various ion channels and pumps that could influence the excitability of the CA1 pyramidal neurons in AS model mice, including voltage-dependent $\mathrm{Na}^{+}$channels NaV1.1, NaV1.2, and NaV1.6 (Fig. 2A), hyperpolarization-activated channels $\mathrm{HCN} 1$ and HCN2 (Fig. $2 B$ ), and $\mathrm{Na}^{+} / \mathrm{K}^{+}$pumps $\alpha 1$-NaKA and $\alpha 3$-NaKA (Fig. 2C). Western blots of hippocampal homogenates revealed that the expression levels of most of these proteins in AS mice were similar to that of their wild-type littermates, except for $\mathrm{NaV} 1.6$ and $\alpha 1$-NaKA. Both proteins exhibit a marked increase in expression levels in the hippocampus of AS mice compared to their wild-type littermates $(\mathrm{WT}=1.0 \pm 0.1, \mathrm{AS}=1.6 \pm 0.2, p<$ 0.05 for NaV1.6; WT $=1.0 \pm 0.1, \mathrm{AS}=1.7 \pm 0.2, p<0.05$ for $\alpha 1$-NaKA) (Fig. 2A,C).

To confirm the increased expression of Nav1.6 and $\alpha 1-\mathrm{NaKA}$ and to determine the localization of these proteins, we performed immunofluorescence microscopy (IF) using hippocampi from 
AS and wild-type mice. Similar to the Western blot analysis, we observed increases in NaV1.6 and $\alpha 1$-NaKA immunofluorescence intensity in the CA1 and CA3 hippocampal subregions in AS mice (Fig. $3 A, B$ ). Interestingly, the increased expression levels of NaV1.6 and $\alpha 1$-NaKA was unique to the hippocampus as we did not observe altered expression of either protein in the somatosensory cortex of the AS mice (Fig. $3 A, B$ ). $\alpha 3$-NaKA IF was not altered (Fig. 3C), consistent with the results of Western blot analysis. Quantification of the differences in IF intensity between AS and WT mice in CA1, CA3, and somatosensory cortex is shown in Figure $3 D$. It should be noted that the increased expression of NaV1.6 in the AS mice was generally restricted to the AIS (Fig. $3 A$ ), whereas the increase in $\alpha 1$ NaKA was throughout the entire somatodendritic region of areas $\mathrm{CA} 1$ and CA3 (Fig. 3B). The differences in $\alpha 1$-NaKA immunoreactivity between AS and wild-type mice for the CA1 pyramidal cell body layer (in relation to DAPI staining) and for the dendrites in the stratum radiatum (in relation to MAP2 staining) were further quantified and found to be significantly elevated in both subcellular locations in the AS mice (Fig. 3E,F).

Because $\alpha 1$-NaKA is known to interact with multiple proteins, we examined the expression of some of these proteins, including cofilin (Lee et al., 2001), IP3R (Miyakawa-Naito et al., 2003), and PP2A (Rajasekaran et al., 2007). However, none of the aforementioned proteins exhibited altered protein expression levels in the AS mice (Fig. 3G).

\section{Ankyrin-G expression is increased in the hippocampus of AS mice}

NaV1.6 and $\alpha 1$-NaKA share a common binding partner in the cytoskeletal adaptor protein ankyrin-G, and $\alpha 1-\mathrm{NaKA}$ also directly interacts with ankyrin-B. Therefore, we determined whether the AS mice exhibited altered expression of ankyrins. Western blot analysis revealed that AS mice exhibit increases in both ankyrin-B and ankyrin-G, especially the higher-molecularweight isoforms that are thought to bind to sodium channels with high affinity (Fig. 4A).

The increases in ankyrin-B and ankyrin-G protein expression levels in the hippocampus of AS mice was confirmed by IF, with increased immunoreactivity for both ankyrins shown in all hippocampal subregions of the AS mice (Fig. $4 B, C$ ). In addition, the increased expression of ankyrin-G in the AS mice was restricted to the AIS (Fig. 4C). In contrast to the hippocampus, no increase in the expression of either ankyrin was observed in the somatosensory cortex (Fig. 4B,C). The expression of another AISspecific protein that binds ankyrin-G, $\beta$ IV-spectrin, was unaltered in the hippocampus of AS mice (Fig. 4D). Quantification of ankyrin-B and ankyrin-G IF in the CA1, CA3, and somatosensory cortex is shown in Figure $4 E$.

Because ankyrin-G is located exclusively at the AIS and regulates the molecular assembly of this region, we examined the expression of proteins that interact with ankyrin-G, including
NF186, NrCAM, $\beta I V$-spectrin, KCNQ2, and KCNQ3 (Fig. $5 A$ ), as well as other proteins that are known to be located at the AIS, including Caspr2, ADAM22, Kv1.1, Kv1.2, and FGF14 (Fig. 5B). Surprisingly, the levels of these AIS-related proteins were unaltered in the AS model mice (Fig. $5 A, B$ ). We also applied IF scanning to some of these AIS-specific proteins, and except for sodium channels and ankyrin-G, we observed no differences in their levels in the AS mice (Fig. 6A-C), consistent with the Western blot analysis. Thus, in the hippocampus of AS mice, the AIS displays an exclusive increase in the expression and density of ankyrin-G and NaV1.6, but not of other scaffold proteins or ion channels.

\section{CA1 and CA3 pyramidal neurons exhibit increased AIS length in AS mice}

Because both NaV1.6 and ankyrin-G are enriched predominantly at the AIS, and ankyrin-G is the central organizing protein of that region, we examined the morphology of the AIS in area CA1 and $\mathrm{CA} 3$ of the AS mice. We observed a significant increase in AIS length in the AS mice compared to WT littermates (WT $=28.3 \pm$ $0.3 \mu \mathrm{m}, \mathrm{AS}=33.1 \pm 0.4 \mu \mathrm{m}, p<0.0001 t$ test and $\mathrm{WT}=29.8 \pm$ $0.2 \mu \mathrm{m}, \mathrm{AS}=33.8 \pm 0.3 \mu \mathrm{m}, p<0.0001 t$ test; for CA1 and CA3 respectively) (Fig. $7 A$ ). This morphological alteration of the AIS was unique to the hippocampus, with no comparable elongation of the AIS in the somatosensory cortex of the AS mice $(\mathrm{WT}=23.8 \pm 0.2 \mu \mathrm{m}, \mathrm{AS}=24.3 \pm 0.2 \mu \mathrm{m})($ Fig. $7 A)$. High-magnification scans of the AIS with NaV1.6 and ankyrin-G costaining in the various regions are shown in Figure $7 B$, and the lower-magnification source images from which these AIS scans were taken are shown in Figure $8 A-C$. It also is evident that the fluorescent intensity for NaV1.6 and ankyrin-G is stronger in the AIS of the AS mice than in their wild-type littermates.

Together with the results described in Figures 1-6, these findings suggest that excitability changes in the hippocampus of AS mice result in altered intrinsic membrane properties, NaV1.6 and ankyrin protein expression levels, and AIS length, and share some 

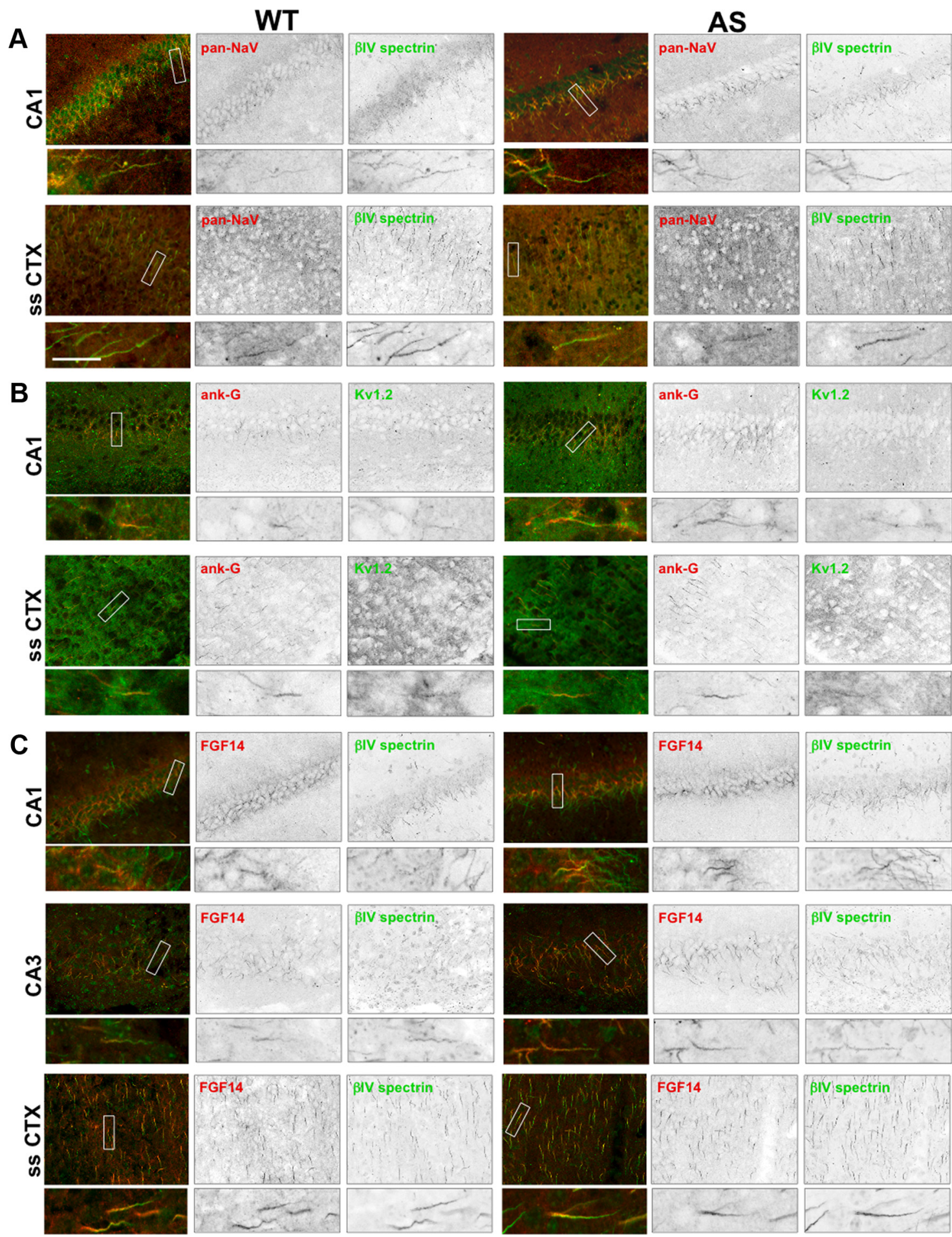

Figure 6. IF scans of other AIS-related proteins indicate no alterations in AS model mice. A-C, IF scans of hippocampal area CA1 and CA3, and the somatosensory cortex (ss CTX) probed for various AlS-related proteins show no change in AS model mice, except for NaVs $(\boldsymbol{A})$ and ankyrin-G $(\boldsymbol{B})$. The upper row is an overview scan of the specific region, and the lower row is a high resolution magnified scan of a specific AIS protein. Rectangles show the areas where the high-resolution AIS samples were taken from. Scale bar, $20 \mu \mathrm{m}$.

similarities to activity-dependent changes in the AIS observed in avian brainstem auditory neurons (Kuba et al., 2010).

\section{$\alpha 1-\mathrm{NaKA}, \mathrm{NaV} 1.6$, and ankyrin-G do not} coimmunoprecipitate with E6-AP

Because E6-AP is an E3-ligase that directs proteins to degradation, and $\alpha 1-\mathrm{NaKA}, \mathrm{NaV1.6}$, and ankyrin-G expression is increased in the hippocampus of AS mice, we hypothesized that they could be E6-AP substrates. Therefore, we investigated whether ankyrin-G, NaV1.6, or $\alpha 1$-NaKA could interact with E6-AP. Coimmunoprecipitation reactions were performed on hippocampal slice homogenates to determine whether protein-protein interactions exist between ankyrin- $\mathrm{G}, \mathrm{NaV} 1.6$, or $\alpha 1$-NaKA proteins and E6-AP. However, our coimmunoprecipitations did not reveal any interaction (Fig. 9A). In addition, we examined the expression levels of $\alpha 1$-NaKA, NaV1.6, 


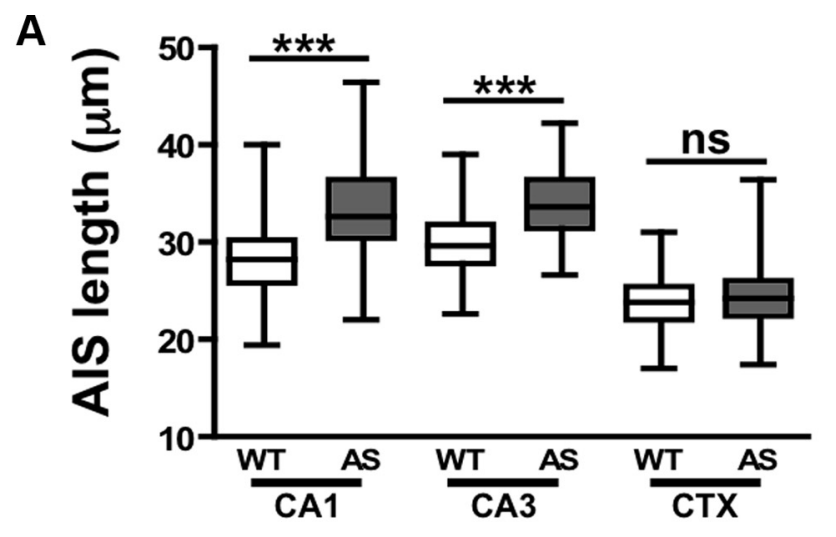

B
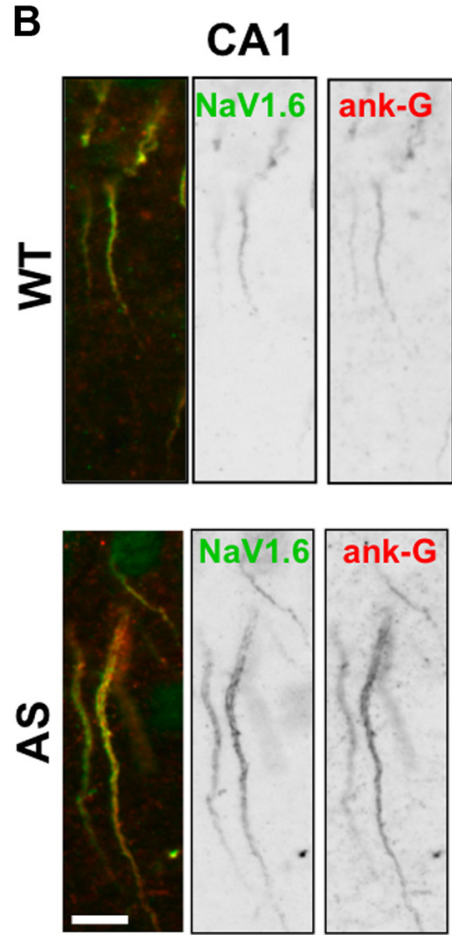
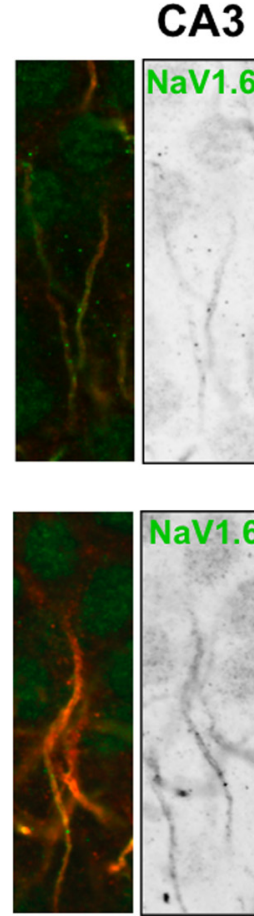

somatosensory
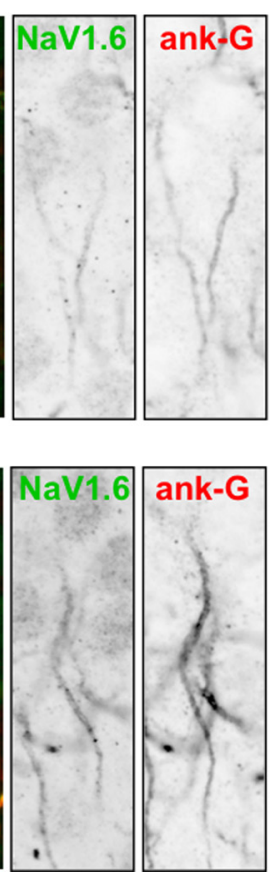

CTX
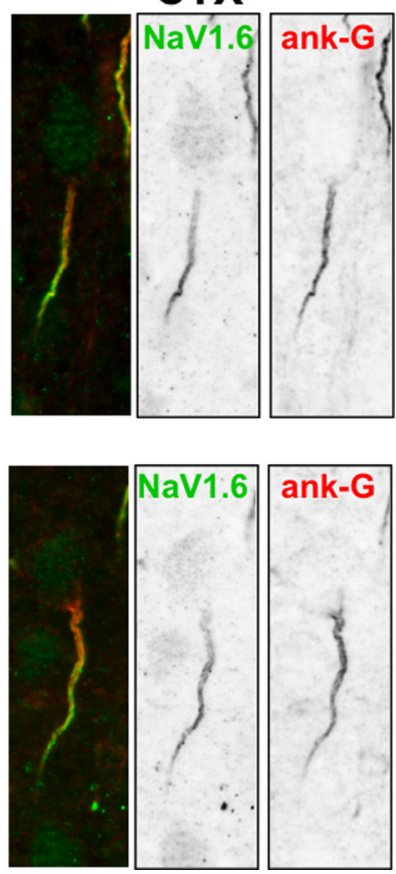

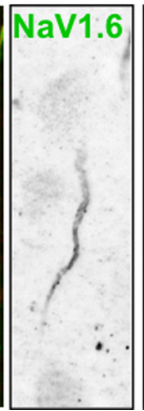

Figure 7. AIS in the hippocampus of AS mice is longer than in wild-type mice. A, AIS length was measured by tracking ankyrin-G IF, demonstrating a significant AIS lengthening in the AS mice of $\sim 18 \%$ and $13 \%$ in hippocampal areas CA1 and CA3 respectively. AIS length in the somatosensory cortex was unaltered (For CA1, WT: $n=126$ cells, 4 mice; AS: $n=140$ cells, 4 mice. For CA3, WT: $n=159$ cells, 4 mice; AS: $n=159$ cells, 4 mice. For somatosensory cortex, WT: $n=221$ cells, 4 mice; AS: $n=223$ cells, 4 mice.). ${ }^{* *}$ denotes statistical significance ( $p<0.001$ ) with a Student's $t$ test. $\boldsymbol{B}$, High-resolution and -magnification sample IF scans of the AIS probed for NaV1.6 and ankyrin-G, in hippocampal areas CA1 and CA3, and the somatosensory cortex in AS mice and WT littermates. Scale bar, $5 \mu \mathrm{m}$.

and ankyrin-G in the somatosensory cortex and found no significant difference between genotypes by either Western blot (Fig. 9B) or IF (Figs. 3, 4). Further, we confirmed that E6-AP was absent from this region, consistent with previous findings (Gustin et al., 2010) (Fig. 9B). We also examined homogenates prepared from the cerebellum, a region known to be affected in AS, to examine AIS components in Purkinje cells. Similar to the somatosensory cortex, there were no expression differences in $\alpha 1-\mathrm{NaKA}, \mathrm{NaV} 1.6$, or ankyrin-G between wild-type and AS mice (Fig. 9C), despite the absence of E6-AP in the cerebellum. Cerebellar IF staining for these proteins supported the findings from the Western blot analysis (Fig. 9D). Together, these findings suggest that $\alpha 1-\mathrm{NaKA}$, $\mathrm{NaV1.6}$, and ankyrin-G are not substrates of E6-AP and also suggest that changes in the levels of these proteins in the hip- pocampus of AS mice is specific to alterations in local network activity.

Increased expression $\alpha 1-\mathrm{NaKA}$ precedes increased expression of NaV1.6 and ankyrin-G and is not related to epileptic activity

We next examined the expression of $\alpha 1-\mathrm{NaKA}, \mathrm{NaV} 1.6$, and ankyrin-G in the hippocampus at different developmental time points. In mice that were 1 week old, the expression of these proteins was similar between the AS mice and their wild-type littermates, despite robust expression of E6-AP in the wild-type mice and its absence in AS mice (Fig. 10A). To our surprise, in mice that were 2 weeks of age, there was a large increase in the expression of $\alpha 1-\mathrm{NaKA}$ in the AS mice, whereas ankyrin-G and NaV1.6 levels were unchanged (Fig. 10B). These results indicate 


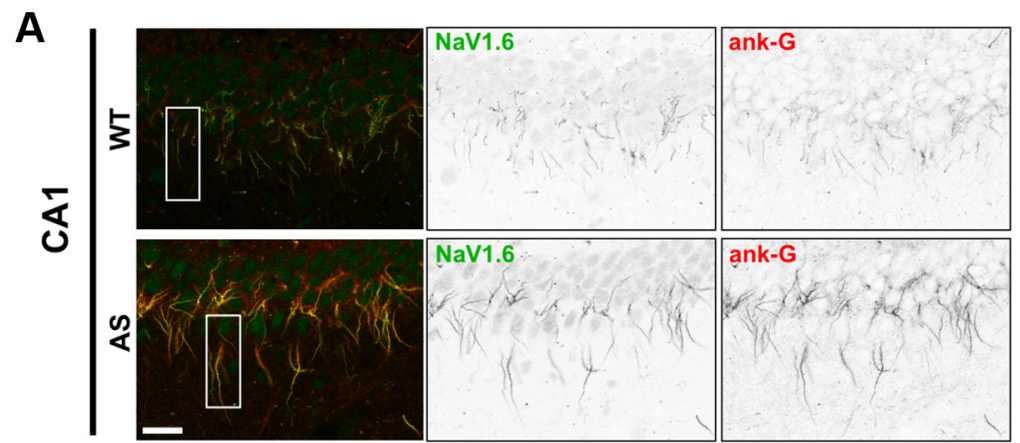

B
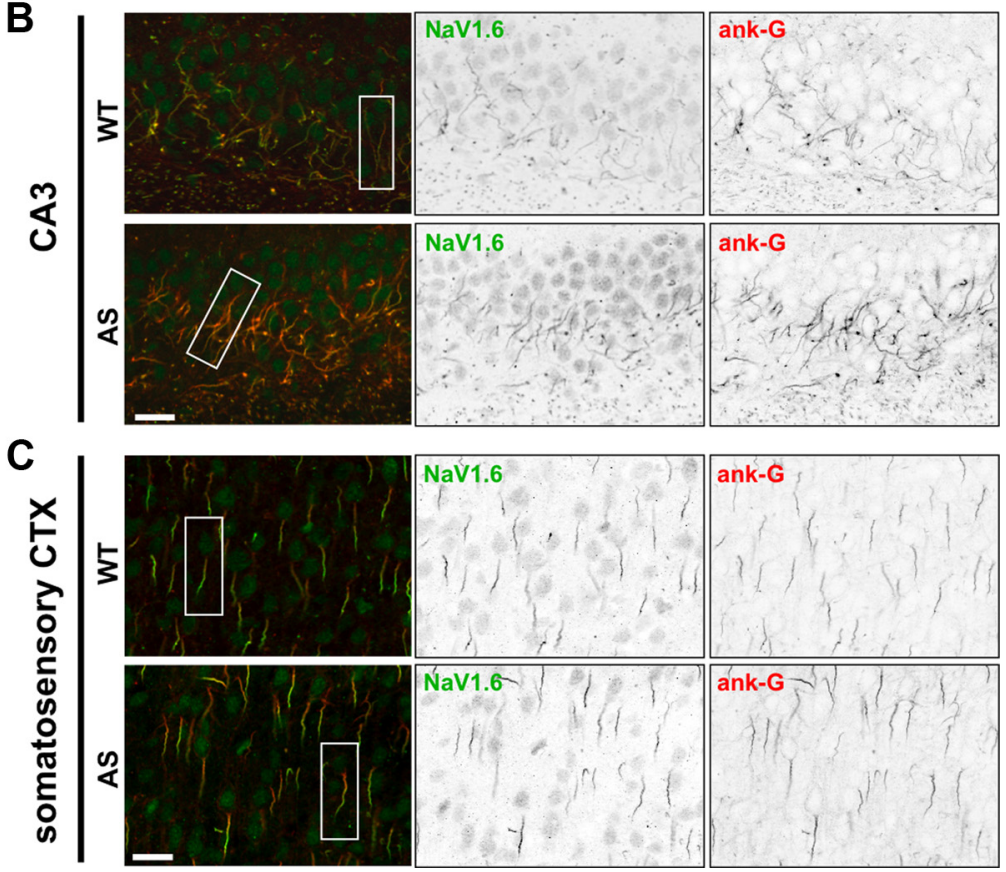

Figure 8. Image sources for the AIS high-resolution scans. IF overview scans of hippocampal areas CA1 (A) and CA3 (B), and the somatosensory cortex ( $C$ probed for NaV1.6 and ankyrin-G. Rectangles show the areas where the high-resolution AIS samples (Fig. $7 B$ ) were taken from. Scale bars, $20 \mu \mathrm{m}$.

that the increase in $\alpha 1-\mathrm{NaKA}$ levels takes place first, followed by increases in the levels NaV1.6 and ankyrin-G, and changes in the AIS.

Because AS mice are known to be susceptible to seizures (Jiang et al., 1998b), we examined whether the alterations in the expression of $\alpha 1-\mathrm{NaKA}$ and ankyrin-G were due to seizures and/or kindling activity. We treated AS mice and their wild-type littermates (3-4 weeks of age) with chronic injections of diazepam for $21 \mathrm{~d}$ at a dose $(12 \mathrm{mg} / \mathrm{kg})$ that is sufficient to inhibit epileptic activity, and examined the expression of $\alpha 1-\mathrm{NaKA}$ and ankyrin-G. The effect of diazepam injection was clearly seen behaviorally when mice were examined $1 \mathrm{~h}$ after the injection as those injected with diazepam became somnolent. We observed no differences in the expression of $\alpha 1-\mathrm{NaKA}$ and ankyrin-G between the vehicle- and diazepam-treated wild-type mice, and the increased expression of the proteins in AS mice remained the same with the diazepam treatment (Fig. 10C,D). These findings suggest that increased expression of $\alpha 1-\mathrm{NaKA}$ and ankyrin-G in AS mice is not driven by epileptic activity. Moreover, these findings are consistent with previous studies showing that AS mice on a C57BL/6 background, especially in the age range of the mice in our study, are not susceptible to epilepsy (Jiang et al., 1998b).

\section{Discussion}

It is well established that hippocampal function is impaired in AS model mice (Jiang et al., 1998b; Weeber et al., 2003). Herein we report that pyramidal neurons in hippocampal area CA1 of AS model mice exhibit altered passive and active intrinsic membrane properties (Table 1, Fig. 1) that are correlated with changes in the expression of specific proteins, suggesting potential mechanisms for these alterations. Increased expression of $\alpha 1-\mathrm{NaKA}$ protein levels (Figs. 2, 3) are correlated with the more hyperpolarized resting membrane potential (Table 1) in the AS mice. Increased expression of NaV1.6 and ankyrin-G (Figs. 2-4) is correlated with a larger action potential amplitude, increased maximal rate of rise of the action potential, and a lower threshold potential, independent of the resting potential (Fig. 1). We also observed with IF that the intracellular localization of these proteins was not altered, but the density of their expression in the AIS was higher (Figs. 3, 4). Furthermore, we observed an increase in the length of the AIS in CA1 pyramidal cells of AS model mice (Fig. 7A). The aforementioned biochemical and morphological alterations in AS mice also were observed in the hippocampal area CA3. Together, these findings suggest that changes in the expression of AIS-related proteins and morphological alterations at the AIS result in abnormal intrinsic membrane properties in CA1 pyramidal neurons in AS model mice.

It recently was shown that the AIS can be modified in response to changes in neuronal excitability. For example, it was shown that increased neuronal excitability induces movement of the AIS away from the cell body (Grubb and Burrone, 2010), whereas blockade of presynaptic input results in intrinsic changes including increased action potential amplitude and maximal rate of rise, decreased action potential threshold, and a morphological change of increased AIS length (Kuba et al., 2010). Our findings in the AS mice share some similarities with the latter studies of blocking the presynaptic input. However, we observed additional, novel AIS modifications including increased expression of the AIS proteins NaV1.6 and ankyrin-G and increased density of these proteins in the AIS (Figs. 3, 4). Furthermore, we found that these changes were specific only to NaV1.6 and ankyrin-G, and did not apply to other AIS-related proteins (Figs. 5, 6). We also found that increased levels of $\alpha 1-\mathrm{NaKA}, \mathrm{NaV1.6}$, and ankyrin-G alterations were not due to epileptic activity, and were not directly related to E6-AP loss of function as an E3 ligase (Figs. 9, 10).

The similarities between our findings and the blockade of presynaptic input model (Kuba et al., 2010) suggest that alterations at the AIS of AS mice might reflect a response to a reduction in neuronal excitability. Unlike this previous study of presynaptic input blockade, we also observed two additional intrinsic changes that occur outside the AIS region: an increased expression of 
A

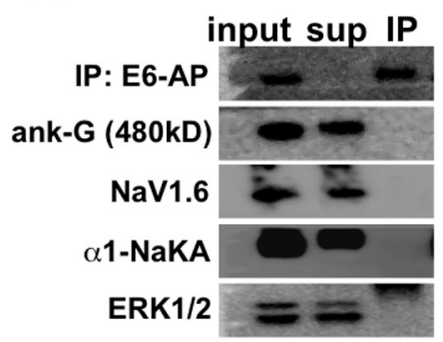

B

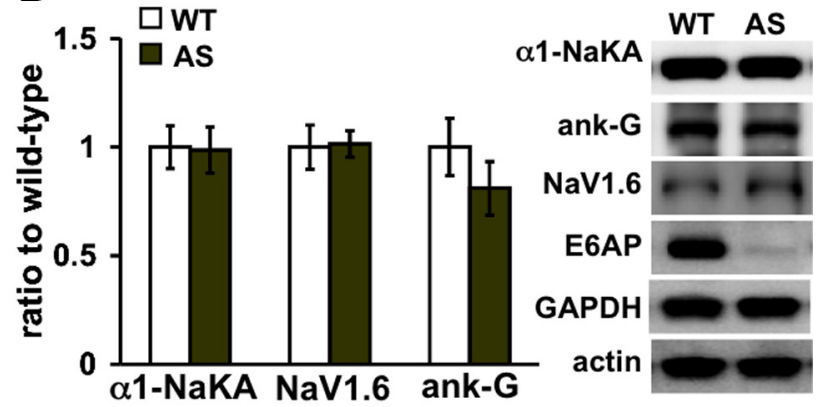

C

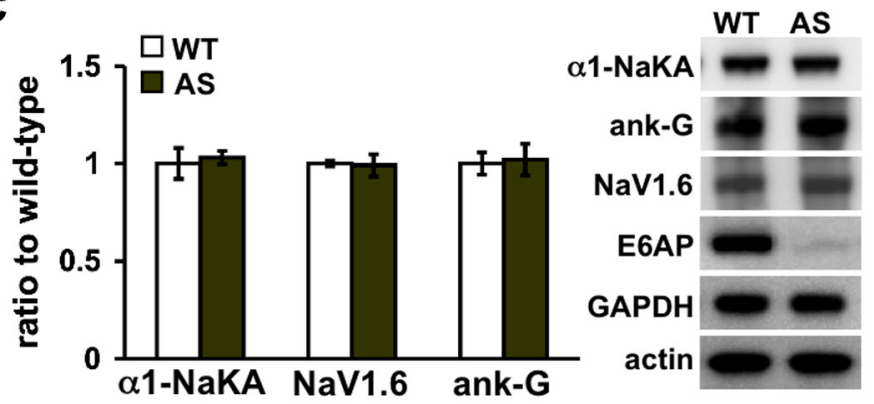

D

WT

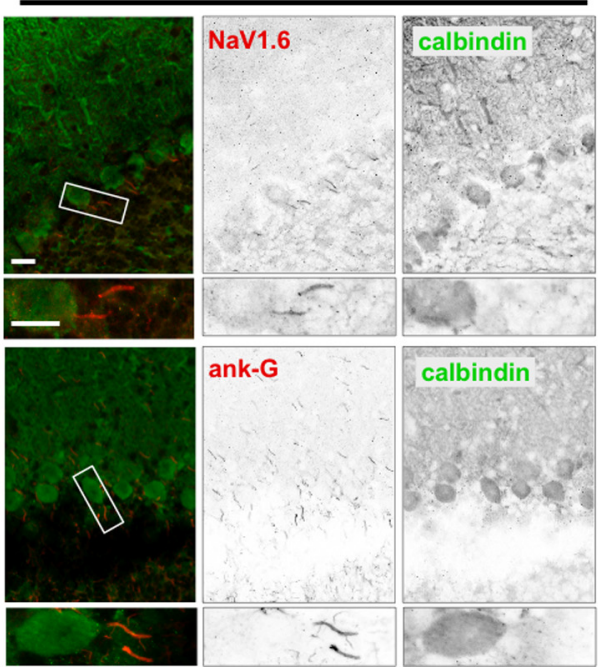

AS

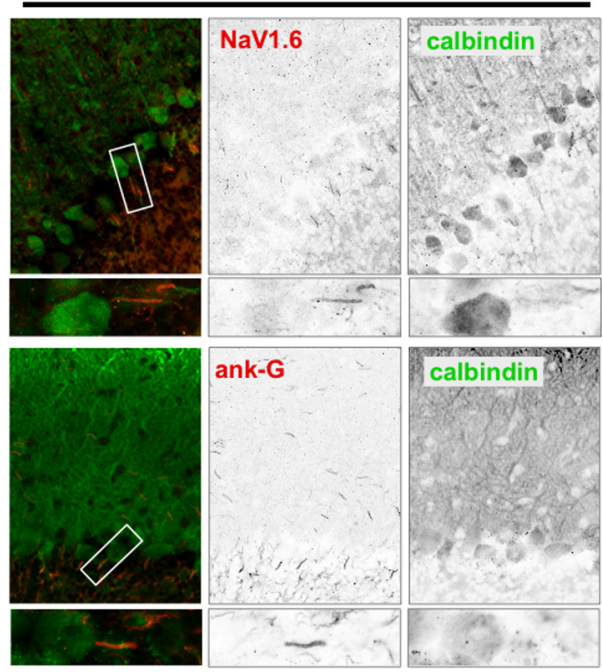

Figure 9. Increased expression of $\alpha 1$-NaKA, NaV1.6 and ankyrin-G is not directly linked to E6-AP loss of function in AS mice. A, Coimmunoprecipitation experiments of hippocampal slices homogenates indicate that E6-AP does not interact with either $\alpha 1$-NaKA or ankyrin-G. Despite a good immunoprecipitation of E6-AP as can be seen in the immunoprecipitated fraction (IP), neither ankyrin-G nor $\alpha 1-N a K A$ are present in that fraction, and they all stayed in the supernatant fraction (sup). All proteins are clearly seen in the homogenate before immunoprecipitation (input). $\boldsymbol{B}, \boldsymbol{C}$, Western blots of somatosensory cortical ( $\boldsymbol{B})$ and cerebellar $(\boldsymbol{C})$ homogenates from AS mice and their WT littermates probed with antibodies to $\alpha 1-N a K A$, NaV1.6, ankyrin-G, and E6-AP (WT: $n=6$ mice; AS: $n=6$ mice). $\boldsymbol{D}$, IF scans of cerebellar slices from AS mice and their WT littermates, probed for calbindin (as a reference), NaV1.6, and ankyrin-G.

$\alpha 1$-NaKA and a hyperpolarized resting potential (Fig. 1). Moreover, because $\alpha 1$-NaKA levels increase during development before the increase in AIS-related protein (NaV1.6 and ankyrin-G) levels (Fig. $10 A, B$ ) and because in brain regions where there is no increase in $\alpha 1$-NaKA there are no AIS-related changes (Fig. 9B$D$ ), we hypothesize that increases in $\alpha 1$-NaKA drive the aforementioned AIS modifications in AS mice. Though these changes are not synaptic, they are consistent with the homeostatic model of intrinsic excitability (Turrigiano and Nelson, 2004), which posits that when a change in excitability in one direction occurs, the neuron will respond with an excitability change in the opposite direction in an attempt to preserve an overall balance of activity. Furthermore, our findings answer some issues raised in view of the reported AIS alterations (Gründemann and Häusser,
2010). We show that less crude interventions, even a single genetic manipulation known to induce an autistic phenotype in humans, can result in changes in intrinsic membrane properties and AIS-specific alterations.

In addition to the AIS changes, our findings of increased expression of $\alpha 1$-NaKA in AS mice might have other repercussions beyond directly affecting intrinsic properties, such as altering multiple types of calcium signaling (McCarren and Alger, 1987; Blaustein and Lederer, 1999). The fact that $\alpha 1$-NaKA was found to be increased in AS, a neurodevelopmental disorder related to autism, is consistent with a previous report of altered NaKA activity in autistic patients (Al-Mosalem et al., 2009; Ji et al., 2009). Moreover, FXYD1, a known NaKA modulator, is a target protein of $\mathrm{MeCP}$, which is the affected protein in Rett 
A

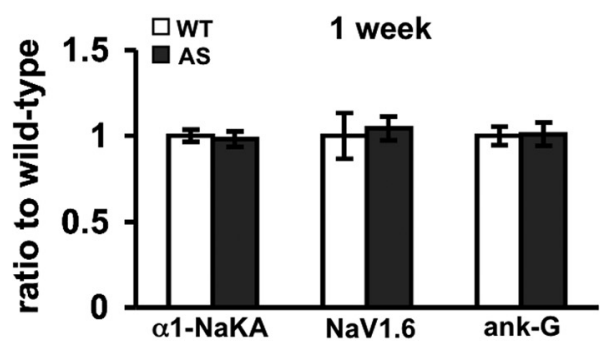

B

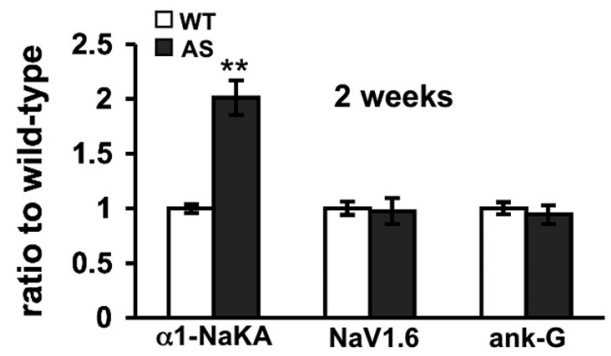

C
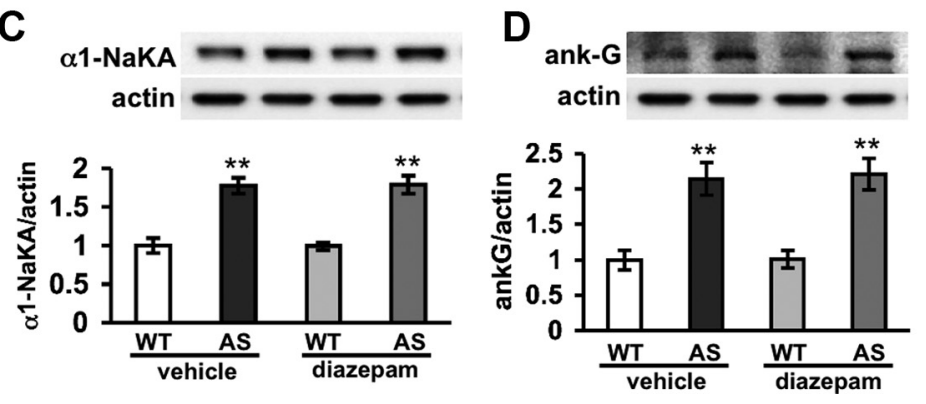

Figure 10. Increased expression of $\alpha 1$-NaKA precedes that of NaV1.6 and ankyrin-G. $\boldsymbol{A}$, Western blots of hippocampal homogenates from AS mice and their WT littermates at the age of 1 week, probed for $\alpha 1-N a K A$, NaV1.6, ankyrin-G, and E6-AP (WT: $n=$ 7 mice; AS: $n=8$ mice). $\boldsymbol{B}$, Western blots of hippocampal homogenates from AS mice and their WT littermates at the age of 2 weeks, probed for $\alpha 1$-NaKA, NaV1.6 and ankyrin-G (WT: $n=7$ mice; AS: $n=7$ mice). $C, D, \alpha 1$-NaKA and ankyrin-G expression is not reversed by anti-epileptic chronic treatment. Western blots of hippocampal homogenates from AS mice and their WT given IP injections of either diazepam (12 mg/kg) or vehicle for 3 weeks, and then probed for $\alpha 1$-NaKA (C) and ankyrin-G (D) $(n=6$ mice for each group) ( $p<0.0012$-way ANOVA; ${ }^{* *}$ denotes $p<0.01$ for comparison of WT to AS in post hoc Bonferroni).

apse formation and function in mental retardation. Curr Opin Neurobiol 20:519-527.

Deng V, Matagne V, Banine $F$, Frerking $M$, Ohliger P, Budden S, Pevsner J, Dissen GA, Sherman LS, Ojeda SR (2007) FXYD1 is an $\mathrm{MeCP} 2$ target gene overexpressed in the brains of Rett syndrome patients and Mecp2null mice. Hum Mol Genet 16:640 -650.

Ey E, Leblond CS, Bourgeron T (2011) Behavioral profiles of mouse models for autism spectrum disorders. Autism Res 4:5-16.

Garrido JJ, Giraud P, Carlier E, Fernandes F, Moussif A, Fache MP, Debanne D, Dargent B (2003) A targeting motif involved in sodium channel clustering at the axonal initial segment. Science 300:2091-2094.

Grubb MS, Burrone J (2010) Activity-dependent relocation of the axon initial segment fine-tunes neuronal excitability. Nature 465:1070-1074.

Gründemann J, Häusser M (2010) Neuroscience: a plastic axonal hotspot. Nature 465:1022-1023.

Gustin RM, Bichell TJ, Bubser M, Daily J, Filonova I, Mrelashvili D, Deutch AY, Colbran RJ, Weeber EJ, Haas KF (2010) Tissuespecific variation of Ube3a protein expression in rodents and in a mouse model of Angelman syndrome. Neurobiol Dis 39:283-291.

Ji L, Chauhan A, Brown WT, Chauhan V (2009) Increased activities of $\mathrm{Na}+/ \mathrm{K}+-\mathrm{ATPase}$ and $\mathrm{Ca} 2+/ \mathrm{Mg} 2+-\mathrm{ATP} a \mathrm{se}$ in the frontal cortex and cerebellum of autistic individuals. Life Sci 85:788-793.

Jiang Y, Tsai TF, Bressler J, Beaudet AL (1998a) Imprinting in Angelman and Prader-Willi syndromes. Curr Opin Genet Dev 8:334-342.

Jiang YH, Armstrong D, Albrecht U, Atkins CM, Noebels JL, Eichele G, Sweatt JD, Beaudet AL (1998b) Mutation of the Angelman ubiquitin ligase in mice causes increased cytoplasmic p53 and deficits of contextual learning and long-term potentiation. Neuron 21:799-811.

Kishino T, Lalande M, Wagstaff J (1997) UBE3A/ E6-AP mutations cause Angelman syndrome. Nat Genet 15:70-73.

Knoll JH, Nicholls RD, Magenis RE, Graham JM

syndrome, another neurodevelopmental disorder (Deng et al., 2007).

In mouse models of neurodevelopmental disorders, studies have focused almost exclusively on synaptic dysfunction (Boda et al., 2010; van Spronsen and Hoogenraad, 2010; Ey et al., 2011). To the best of our knowledge, this is the first report to demonstrate altered intrinsic membrane properties, increased expression levels of $\alpha 1-\mathrm{NaKA}$, and abnormalities in AIS morphology and protein composition in mice that model a human neurodevelopmental disorder. Moreover, our report is one of the first describing the aforementioned AIS pathologies in the mammalian brain in vivo. We suggest that AS model mice might serve as a platform for examining extrasynaptic homeostatic plasticity and its involvement in human neurodevelopmental disorders.

\section{References}

Albrecht U, Sutcliffe JS, Cattanach BM, Beechey CV, Armstrong D, Eichele G, Beaudet AL (1997) Imprinted expression of the murine Angelman syndrome gene, Ube3a, in hippocampal and Purkinje neurons. Nat Genet 17:75-78.

Al-Mosalem OA, El-Ansary A, Attas O, Al-Ayadhi L (2009) Metabolic biomarkers related to energy metabolism in Saudi autistic children. Clin Biochem 42:949-957.

Blaustein MP, Lederer WJ (1999) Sodium/calcium exchange: its physiological implications. Physiol Rev 79:763-854.

Boda B, Dubos A, Muller D (2010) Signaling mechanisms regulating syn-
Jr, Lalande M, Latt SA (1989) Angelman and Prader-Willi syndromes share a common chromosome 15 deletion but differ in parental origin of the deletion. Am J Med Genet 32:285-290.

Kole MH, Stuart GJ (2008) Is action potential threshold lowest in the axon? Nat Neurosci 11:1253-1255.

Kole MH, Ilschner SU, Kampa BM, Williams SR, Ruben PC, Stuart GJ (2008) Action potential generation requires a high sodium channel density in the axon initial segment. Nat Neurosci 11:178-186.

Kuba H, Oichi Y, Ohmori H (2010) Presynaptic activity regulates $\mathrm{Na}(+)$ channel distribution at the axon initial segment. Nature 465:1075-1078.

Lee K, Jung J, Kim M, Guidotti G (2001) Interaction of the alpha subunit of $\mathrm{Na}, \mathrm{K}-\mathrm{ATP}$ ase with cofilin. Biochem J 353:377-385.

Lemaillet G, Walker B, Lambert S (2003) Identification of a conserved ankyrin-binding motif in the family of sodium channel alpha subunits. J Biol Chem 278:27333-27339.

Lossie AC, Whitney MM, Amidon D, Dong HJ, Chen P, Theriaque D, Hutson A, Nicholls RD, Zori RT, Williams CA, Driscoll DJ (2001) Distinct phenotypes distinguish the molecular classes of Angelman syndrome. J Med Genet 38:834-845.

Matsuura T, Sutcliffe JS, Fang P, Galjaard RJ, Jiang YH, Benton CS, Rommens JM, Beaudet AL (1997) De novo truncating mutations in E6-AP ubiquitin-protein ligase gene (UBE3A) in Angelman syndrome. Nat Genet 15:74-77.

McCarren M, Alger BE (1987) Sodium-potassium pump inhibitors increase neuronal excitability in the rat hippocampal slice: role of a Ca2+dependent conductance. J Neurophysiol 57:496-509.

Miyakawa-Naito A, Uhlén P, Lal M, Aizman O, Mikoshiba K, Brismar H, 
Zelenin S, Aperia A (2003) Cell signaling microdomain with Na,KATPase and inositol 1,4,5-trisphosphate receptor generates calcium oscillations. J Biol Chem 278:50355-50361.

Rajasekaran SA, Barwe SP, Gopal J, Ryazantsev S, Schneeberger EE, Rajasekaran AK (2007) Na-K-ATPase regulates tight junction permeability through occludin phosphorylation in pancreatic epithelial cells. Am J Physiol Gastrointest Liver Physiol 292:G124-133.

Rasband MN, Taylor CM, Bansal R (2003) Paranodal transverse bands are required for maintenance but not initiation of Nav1.6 sodium channel clustering in CNS optic nerve axons. Glia 44:173-182.

Rhodes KJ, Keilbaugh SA, Barrezueta NX, Lopez KL, Trimmer JS (1995) Association and colocalization of $\mathrm{K}^{+}$channel $\alpha$ - and $\beta$-subunit polypeptides in rat brain. J Neurosci 15:5360-5371.

Schafer DP, Bansal R, Hedstrom KL, Pfeiffer SE, Rasband MN (2004) Does paranode formation and maintenance require partitioning of neurofascin 155 into lipid rafts? J Neurosci 24:3176-3185.

Sutcliffe JS, Jiang YH, Galijaard RJ, Matsuura T, Fang P, Kubota T, Christian SL, Bressler J, Cattanach B, Ledbetter DH, Beaudet AL (1997) The E6-Ap ubiquitin-protein ligase (UBE3A) gene is localized within a narrowed Angelman syndrome critical region. Genome Res 7:368-377.

Turrigiano GG, Nelson SB (2004) Homeostatic plasticity in the developing nervous system. Nat Rev Neurosci 5:97-107. van Spronsen M, Hoogenraad CC (2010) Synapse pathology in psychiatric and neurologic disease. Curr Neurol Neurosci Rep 10:207-214.

van Woerden GM, Harris KD, Hojjati MR, Gustin RM, Qiu S, de Avila Freire R, Jiang YH, Elgersma Y, Weeber EJ (2007) Rescue of neurological deficits in a mouse model for Angelman syndrome by reduction of alphaCaMKII inhibitory phosphorylation. Nat Neurosci 10:280-282.

Weeber EJ, Jiang YH, Elgersma Y, Varga AW, Carrasquillo Y, Brown SE, Christian JM, Mirnikjoo B, Silva A, Beaudet AL, Sweatt JD (2003) Derangements of hippocampal calcium/calmodulin-dependent protein kinase II in a mouse model for Angelman mental retardation syndrome. J Neurosci 23:2634-2644.

Williams CA, Beaudet AL, Clayton-Smith J, Knoll JH, Kyllerman M, Laan LA, Magenis RE, Moncla A, Schinzel AA, Summers JA, Wagstaff J (2006) Angelman syndrome 2005: updated consensus for diagnostic criteria. Am J Med Genet A 140:413-418.

Yang Y, Lacas-Gervais S, Morest DK, Solimena M, Rasband MN (2004) $\beta I V$ spectrins are essential for membrane stability and the molecular organization of nodes of Ranvier. J Neurosci 24:7230-7240.

Zhou D, Lambert S, Malen PL, Carpenter S, Boland LM, Bennett V (1998) AnkyrinG is required for clustering of voltage-gated $\mathrm{Na}$ channels at axon initial segments and for normal action potential firing. J Cell Biol 143: 1295-1304. 